Check for updates

Cite this: RSC Adv., 2019, 9, 8016

Received 21st December 2018 Accepted 15th February 2019

DOI: $10.1039 / c 8 r a 10485 a$

rsc.li/rsc-advances

\section{Indirect study of the effect of $\alpha$-tocopherol and acetylsalicylic acid on the mineral composition of bone tissue in the offspring of female rats treated with 2,3,7,8-tetrachlorodibenzo-p-dioxin: long- term observations}

\author{
Maciej Dobrzynski, (DD *a Piotr Kuropka, (DD b Malgorzata Tarnowska, ${ }^{\mathrm{c}}$ Krzysztof Dudek, ${ }^{\mathrm{d}}$ \\ Marzena Styczynska, ${ }^{e}$ Anna Leskow, (D) Sara Targonska ${ }^{\mathrm{f}}$ and Rafal J. Wiglusz (D) ${ }^{* f g}$ \\ This paper discusses problems related to the influence of 2,3,7,8-tetrachlorodibenzo- $p$-dioxin (TCDD) on \\ the mineral composition of the calvaria in the offspring of female rats. The female rats were administered \\ with a single dose of TCDD and subsequently, after three-weeks, with $\alpha$-tocopherol or acetylsalicylic acid. \\ The research focused on analysis of the main mineral elements (Ca, Mg, Fe, Zn). The aim of the study was to \\ determine the effect of dioxins and various doses of drugs on bone mineral composition in a six-month \\ observation period. The mineral composition was analyzed using an atomic spectrometry method. Data \\ were statistically analyzed and verified at a significance level of $p=0.05$. The use of $\alpha$-tocopherol \\ normalizes bone resorption and formation disturbed by TCDD, maintaining the content of the studied \\ elements at the physiological level. In turn, administration of acetylsalicylic acid limits the bone \\ resorption process, which affects the element content.
}

\section{Introduction}

2,3,7,8-Tetrachlorodibenzo- $p$-dioxin (TCDD) is one of the most toxic substances and environmental poisons, and is classified as a so-called persistent organic pollutant (POP). Since the 1st of June, 1997 TCDD has also been included in the A list of carcinogens published by the International Agency for Research on Cancer (IARC), with its carcinogenicity being confirmed by research conducted on animals. ${ }^{1,2}$

Dioxins can be created in a number of technological processes, but primarily they are created as a result of combustion of various organic substances in the presence of

${ }^{a}$ Department of Conservative Dentistry and Pedodontics, The Faculty of Dentistry, Wroclaw Medical University, Wroclaw, Poland. E-mail: maciej.dobrzynski@umed. wroc.pl

${ }^{b}$ Department of Histology and Embryology, Faculty of Veterinary Medicine, Wroclaw University of Environmental and Life Sciences, Wroclaw, Poland

'Department of Nervous System Diseases, Faculty of Health Science, Wroclaw Medical University, Wroclaw, Poland

${ }^{d}$ Department of Logistics and Transport Systems, Faculty of Mechanical Engineering, Wroclaw University of Science and Technology, Wroclaw, Poland

${ }^{e}$ Department of Human Nutrition, Faculty of Food Science, Wroclaw University of Environmental and Life Sciences, Wroclaw, Poland

${ }^{f}$ Institute of Low Temperature and Structure Research, Polish Academy of Science, Wroclaw, Poland. E-mail: r.wiglusz@intibs.pl

${ }^{g}$ Centre for Advanced Materials and Smart Structures, Polish Academy of Sciences, Wroclaw, Poland chlorine in burning temperatures from 200 to $900{ }^{\circ} \mathrm{C}$, with an insufficient amount of oxygen and in the presence of water. ${ }^{3,4}$ In spite of the strict obligations arising from the provisions of the Stockholm Convention, the emission of dioxins into the environment is still growing. ${ }^{5}$ Important sources of dioxin emission are combustion engines, such as diesel engines, engine oil leaks and poorly secured garbage dumps. ${ }^{1,4}$ The release of dioxins into the environment as by-products of technological processes is also observed, for example, in the metallurgy, chemical, paper, paint and textile industry or in the process of the production of pesticides. ${ }^{6,7}$ Released dioxins accumulate in the food chain, causing a number of negative biological effects in the next generation of animals. ${ }^{1,8,9}$ Dioxins have no color, taste or smell, and therefore are organoleptically undetectable. Their physical and chemical properties can make these substances a powerful weapon for terrorists, such as the poisoning of the former Ukrainian President Viktor Yushchenko in 2004. ${ }^{10}$

The molecular effect of dioxins is the activation of the transcription of specific genes including enzymes metabolizing xenobiotics and various forms of cytochrome P450. ${ }^{11-13}$ In many cases, the reactions catalyzed by this cytochrome result in the formation of toxic metabolites, and mutagenic and carcinogenic intermediate products. ${ }^{13}$ These products affect the expression of genes that control the growth and differentiation of cells and the expression of genes for hormones, enzymes and growth factors., ${ }^{3,714}$ These genes are controlled by the cytoplasmatic aryl hydrocarbon receptor (AhR) and the aryl 
hydrocarbon receptor nuclear translocator (ARNT).,13,15,16 Dioxins which connect with the AhR cause a migration of the receptor into the cell nucleus, which induces the expression of genes for cytochromes. ${ }^{17-19}$ Furthermore, dioxins have an affinity for the estrogen receptor and owing to this they contribute to reproductive disorders and behavioral disorders associated with the occurrence of changes in the expression of receptors in the central nervous system structures. ${ }^{17}$

The most significant documented adverse effects of dioxins include: chloracne, changes in the level of thyroid hormones with impairment of the psychomotor abilities, fertility problems or infertility, increased concentration of alpha- and betaglobulins and delayed immune response, and carcinogenic and teratogenic effects in humans.,.$^{3,11,20-24}$ Many studies involving intoxicated animals reported the following symptoms: porphyria, hepatomegaly, atrophy of the thymus and peripheral lymph nodes, cancers, and inhibition of ovulation..$^{3,20,25-28}$ In rats poisoned with dioxins hypoplasia of the bones was also observed, which correlates with the findings of other authors working with a model of birds consuming fish which contained dioxins. ${ }^{4,29,30}$

In spite of the wide range of studies on the biological effects of dioxins on humans and animals, there are only a few publications that have assessed the impact of dioxins on bone tissue, taking into account the mineral composition.

The major components of the bone tissue matrix are calcium and magnesium phosphates. The concentration of the salts of these elements in the bone tissue matrix influences the hardness and elasticity. Moreover, numerous metals, such as zinc and iron, have important influences as co-factors of enzymes on bone development and mineralization..$^{31,32}$ The process of mineralization of young bone is controlled by a group of proteins in which osteonectin, osteocalcin and alkaline phosphatase play the most important roles. Many xenobiotics, including dioxins, negatively influence the biosynthesis of these proteins. A reduction in the calcium and magnesium content of bone tissue could be a symptom of a microstructure disorder. ${ }^{4,33}$

Consequently, dioxins can affect the bone structure, particularly during the growth period. ${ }^{28}$ On the other hand, by affecting the activity of some hormones (estrogens, corticosterone, T3), dioxins can modify the correct development of hard tissues.11,34-36 Owing to the fact that dioxins influence the concentration of the active form of vitamin D3, they also inhibit the activity of fibroblasts. ${ }^{37}$ In this context, there is a need to search for drugs which can prevent formation of the AhR-dioxin complex and therefore inhibit the formation of toxic metabolites. It has been shown in recent studies that two well-known substances, $\boldsymbol{\alpha}$-tocopherol and acetylsalicylic acid (ASA), have properties that can reduce the effects of dioxins poisoning. $3,31,36,38,39$

Nowadays, monitoring the constant exposure of humans and animals to dioxins and their influence on bone mineralization is essential for the prevention of dioxin intoxication and the development of effective pharmacological treatment methods 3,40-43

Acetylsalicylic acid is a non-steroidal anti-inflammatory drug (NSAID) which is a febrifugal, analgesic and anti- inflammatory. ${ }^{\mathbf{4 4 5}}$ An important issue is the fact that ASA demonstrates a beneficial influence on bone mineral density $(\mathrm{BMD})^{46,47}$ and studies by MacDonald et al. showed that ASA is an inhibitor of AhR and significantly decreases the binding of TCDD to this receptor. ${ }^{36}$ Vitamin $\mathrm{E}$ is a family consisting of eight compounds with a similar structure, out of which $\alpha$-tocopherol exhibits the highest biological activity. This is one of the most commonly used forms of pharmacological tocopherols ${ }^{48}$ and has an antagonistic effect on the aryl hydrocarbon receptor. ${ }^{17,38,39,49}$

Owing to the fact that exposure of the mother to TCDD can interfere with offspring skeletal development, the aim of this study is to determine whether $\alpha$-tocopherol or acetylsalicylic acid influences the effect of dioxin on the bone mineral composition in the offspring of TCDD-intoxicated females, during a long-term observation.

\section{Material and methods}

\section{Animals}

The experiment was conducted on female Buffalo rats aged 9-11 week and weighing 130-150 grams, which were obtained from a rat breeding farm. During the experiment, the animals were kept in an air-conditioned room under the following conditions: air exchanged 15 times per hour, air temperature $22{ }^{\circ} \mathrm{C}$, humidity $55 \%$, light cycle $12 / 12$ hours. Animals were kept in polystyrene cages with access to Labofeed $\mathrm{H}$ feed and water.

\section{Division of animals}

Rats were randomized and divided into four groups, with six animals in each group:

(I) Female control group (FC), not treated with any chemicals.

(II) Group of females (FTCDD) treated with a solution of TCDD with a single dose of $5 \mu \mathrm{g} \mathrm{kg}^{-1}$ of body mass, administered i.m.

(III) Group of females (FTCDD + E) treated with a solution of TCDD in a single dose of $5 \mu \mathrm{g} \mathrm{kg}^{-1}$ of body mass i.m. and with a solution of $\alpha$-tocopherol acetate for 3 weeks at a dose of $30 \mathrm{mg}$ $\mathrm{kg}^{-1}$ of body mass per day s.c.

(IV) Group of females (FTCDD + ASA) treated with a solution of TCDD, in a single dose of $5 \mu \mathrm{g} \mathrm{kg}{ }^{-1}$ of body mass $i . m$. and treated with a suspension of ASA in a starch solution for 3

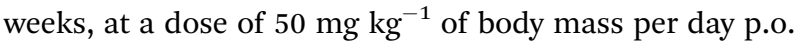

The TCDD, $\alpha$-tocopherol and ASA doses were determined based on previously published data. ${ }^{50}$

After a period of 3 weeks following administration of TCDD in the individual groups (FTCDD, FTCDD + E, FTCDD + ASA), the above-mentioned groups and the FC group were mated with males that had not been treated with any chemicals. After a period of 7 days after mating, pregnant females were placed in separate cages.

After around 21 days of pregnancy, the births took place. The offspring were divided into four research groups, each consisting of 24 animals, which were euthanized after 1, 4, 6 and 24 
weeks of life. Six randomly selected individuals were euthanized at each chosen date.

The offspring were classified into the following groups:

Group 1: offspring (OC) from FC females.

Group 2: offspring (OTCDD) from FTCDD females.

Group 3: offspring (OTCDD + E) from FTCDD + E females.

Group 4: offspring (OTCDD + ASA) from FTCDD + ASA females.

Rats underwent barbiturate anesthesia prior to the collection of biological material for testing. Thiopental (Biochemie $\mathrm{GmbH}$ ) was injected intraperitoneally at a dose of $120 \mathrm{mg} \mathrm{kg}^{-1}$ of body mass.

The calvaria was removed, stored at $-20{ }^{\circ} \mathrm{C}$ in sterile boxes, and then analyzed for calcium, magnesium, iron and zinc content.

\section{Substances and compounds}

The following chemicals were used in the experiment:

$\alpha$-Tocopherol acetate (oil solution of the drug prepared individually by Hasco-Lek S. A., Poland), acetylsalicylic acid (Bayer, Germany), thiopental (Biochemie $\mathrm{GmbH}$, Austria), and 2,3,7,8-tetrachlorodibenzo- $p$-dioxin (Greyhound Chromatography and Allied Chemicals, UK) dissolved in dimethyl sulfoxide (DMSO; Sigma-Aldrich, Poland) at a concentration of $5 \mu \mathrm{g}$ $\mathrm{ml}^{-1}$.

\section{Determination of content of chemical elements in calvaria}

The elements were determined on the basis of the atomic spectrometry method.

\section{Wet mineralization of samples in a closed microwave system}

Concentrated nitric acid (V) $\left(5 \mathrm{~cm}^{3}\right)$ and $1 \mathrm{~cm}^{3}$ of concentrated hydrogen peroxide were added to the homogeneous sample (weight from 0.1 to $0.5 \mathrm{~g}$ ) and then the samples were mineralized with the use of a microwave accelerated reaction system (MARS) (CEM Corporation, 3100 Smith Farm Road, Matthews, NC 2810, 704-821-7015). The mineralizates were transferred quantitatively into measurement vessels with a capacity of 10 $\mathrm{cm}^{3}$ with the use of redistilled water. The mineralization process was carried out in accordance with the Polish standard PN-EN 13805-2014-11. ${ }^{51}$

Analysis of the calcium content was performed in an acetylene/oxygen flame by means of emission atomic spectrometry using an atomic absorption spectrometer SpectraAA with an AA240FS attachment (Varian Inc. Australia Pty Ltd, Mulgrave Victoria Australia. Varian, Inc.). Measurements of the calcium was performed according to the Laboratory Procedure PB-06/AAS based on standard no. 13805-2014-11. ${ }^{51}$

Analysis of the magnesium, zinc and iron content was performed in an acetylene/oxygen flame by means of absorption atomic spectrometry with the use of an atomic absorption spectrometer SpectraAA with the AA240FS attachment (Varian). The measurements of magnesium, zinc and iron were performed according to the standard PN-EN 14084:2004.

\section{Statistical analysis}

A summary of the research results included: developing descriptive statistics (mean, standard deviation, median, extreme values: maximum and minimum); checking the normality of the distribution of characteristics (content result) with the use of the Shapiro-Wilk test; checking the homogeneity of the content result variances by means of Bartlett's test; and verifying the hypotheses concerning the equality of the level of measurable characteristics with a normal distribution in more than two groups using analysis of variance (ANOVA). The significance of the differences in the level of elements in the studied groups of offspring between pairs of age subgroups was verified by means of post hoc tests (Tukey's test). The correlation between the obtained results of the element content were calculated basing on Pearson's ( $r$ ) or Spearman's (rho) ratios. All of the hypotheses were verified at the significance level of $p=$ 0.05 . Statistical analysis was performed using the statistical software package STATISTICA 13.0. Owing to small discrepancies in the obtained values, mean values were subjected to further statistical evaluation.

\section{Live subject statement}

All materials in the present study were obtained according to the appropriate ethical guidelines and requirements applicable in such cases and were approved by the Local Ethics Council for Animal Experiments, Wroclaw, Republic of Poland (permission number: 38/2009). All procedures were carried out in accordance with the appropriate guidelines and regulations of the Republic of Poland.

\section{Results}

\section{Statistical analysis}

Calcium. In group 1 the content of Ca found in the calvaria bones of the neonates ( 1 week) and in the 4 th and 6 th week was maintained at a level from 35.2 to $38.2 \mathrm{mg} \mathrm{g}^{-1}$, and in the 24 th week, it significantly increased statistically to values of $64.7 \pm$ $5.1 \mathrm{mg} \mathrm{g}^{-1}$ (Table 1).

In group 2, in the 4 th week, a significant increase in the content of $\mathrm{Ca}(80.7 \pm 54.9)$ was observed and this dropped to $45.8 \pm 4.1 \mathrm{mg} \mathrm{g}^{-1}$ in the 6 th week of the experiment.

In group 3, a big increase in the content of Ca to $132.7 \mathrm{mg} \mathrm{g}^{-1}$ was observed in the 4 th week. In the 6th and 24th weeks a statistically significant content decrease was observed to 52.7 and $74.8 \mathrm{mg} \mathrm{g}^{-1}$.

In group 4, the content of Ca was maintained at a level close to that obtained in group 1 , however, a statistically significant growth in the content of $\mathrm{Ca}$ in the bones in the 24th week was not observed (Table 1).

The calcium content significantly depends on the pharmacological substances administered, which has been shown by means of the interactions observed between the studied groups. An increase in the level of $\mathrm{Ca}$ in comparison to group 1 was observed in the 4th week of the experiment, with the exception of group 2 in which a decrease was observed in the 6th week, and then another increase in the 24th week. The largest, 
Table 1 Content of calcium, magnesium, iron and zinc in the calvaria and the relationships occurring in the analyzed groups ${ }^{a}$

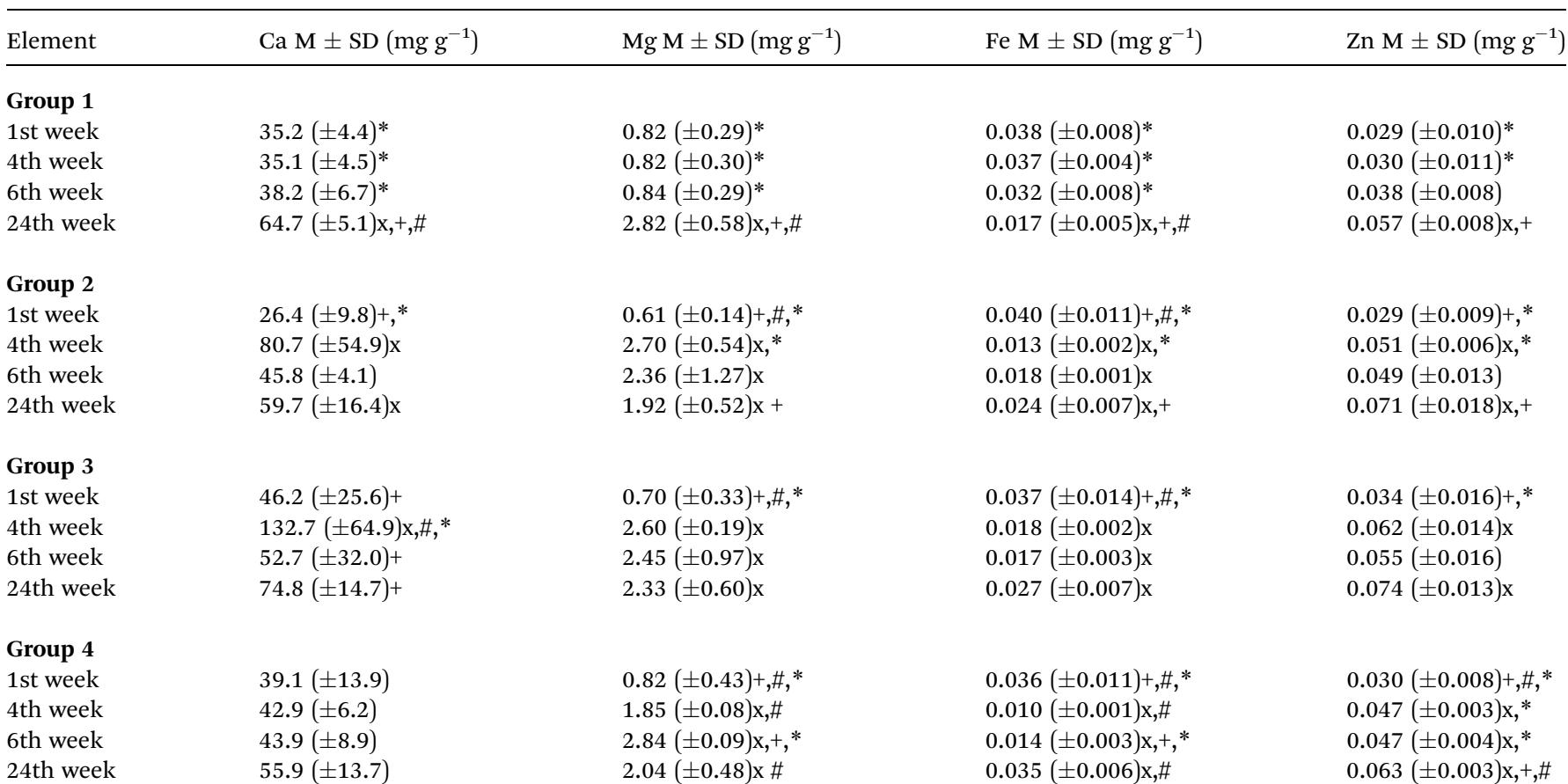

${ }^{a} M=$ mean value; $\mathrm{SD}=$ standard deviation; statistical significance: $v$ s. 1 st week $=\mathrm{x} ; 4$ th week $=+; 6$ th week $=\# ; 24$ th week $=*$.

approximately 3 -fold, increase in the content of Ca compared with group 1 was observed in group 3, which positively correlated with the greatest increase in the calcium content in the 4 th week (Fig. 1 and 2).

Magnesium. The magnesium level in the calvaria of all of the neonate groups differed significantly $(p>0.05)$. In group 1 the concentration of $\mathrm{Mg}$ remained at the same level, and increased by a statistically significant amount in the 24th week $0.82 \pm$ $0.29 \mathrm{mg} \mathrm{g}^{-1}$ vs. $\left.2.82 \pm 0.58 \mathrm{mg} \mathrm{g}^{-1} ; p<0.001\right)$. In the offspring of
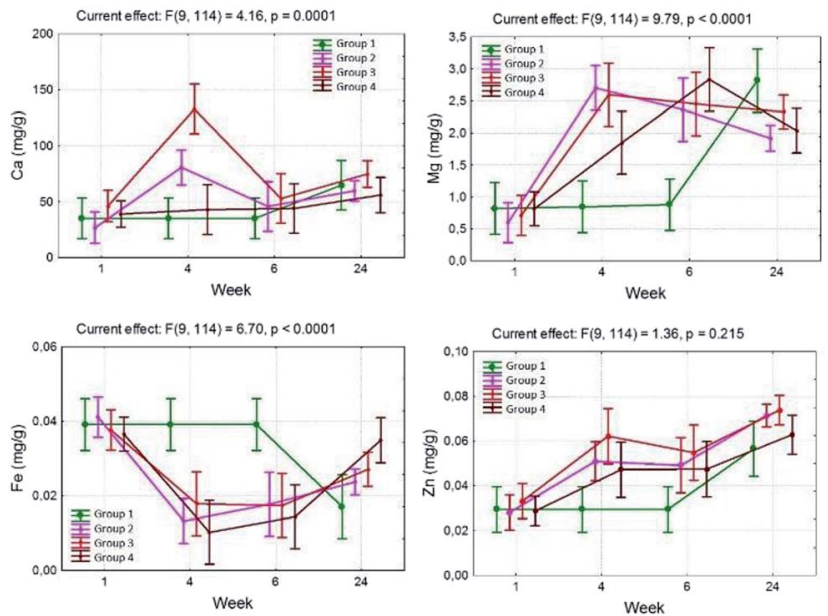

Fig. 1 Diagrams illustrating the influence of the analyzed interaction time $\times$ TCDD on the content of chemical elements in individual research groups, from the top, reading left to right: calcium, magnesium, iron, zinc. females from group 2 and 3 a statistically significant increase in the magnesium level was observed as soon as in the 4 th week $\left(2.70 \pm 0.54\right.$ and $2.60 \pm 0.19 \mathrm{mg} \mathrm{g}^{-1}$ respectively) and in group 4 in the 6th week $\left(2.84 \pm 0.09 \mathrm{mg} \mathrm{g}^{-1}\right)$. The increase was nonlinear and in the 24th week the level of $\mathrm{Mg}$ was lower than the maximum value achieved previously. The results show that for both of the analyzed factors, that is the time and the type of pharmacological substance, significantly influenced $(p<0.001)$ the magnesium content in bones. TCDD caused an increase in the $\mathrm{Mg}$ content in the bones of the calvaria (Table 1). An important interaction also occurred between the time and the pharmacological factor. In the group 1 , a statistically significant increase in the magnesium content was observed in the 24th week of the experiment. In groups 2 and 3, the increase in the

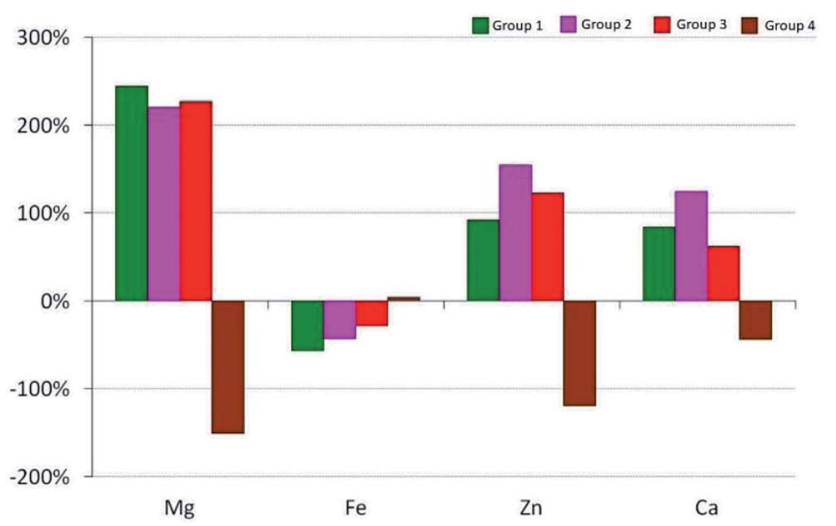

Fig. 2 Relative change in the content of the analyzed elements $\Delta C_{24}$ $(\%)$ in the calvaria after 24 weeks for the experimental groups. 
$\mathrm{Mg}$ content was observed as soon as in the 4 th week, and in group 4 the maximum increase was shown in the 6 th week of the experiment (Fig. 1 and 2).

Iron. The average iron content in the calvaria in rats from group 1 ranged from 0.017 to $0.038 \mathrm{mg} \mathrm{g}^{-1}$. The level of Fe in group 1 tended to slightly decrease with age, until the 24th week, when the decrease became statistically significant (Table 1).

In groups 2, 3 and 4 in the neonatal period ( 1 week) the determined content of Fe was comparable to group 1 and was $0.040,0.037$ and $0.036 \mathrm{mg} \mathrm{g}^{-1}$, respectively (Table 1).

In the 4 th week, in groups 2, 3 and 4 a statistically significant decrease in the content of Fe, compared with group 1, was observed and amounted to $0.013,0.018$ and $0.010 \mathrm{mg} \mathrm{g}^{-1}$ respectively (Table 1 ).

In the 6 th week in group 3 , the iron content significantly increased compared with the 4 th week, and this trend continued until the 24th week, and the levels achieved during that time were statistically significantly higher than in group 1 . At the same time in group 4, the content of Fe increased during the 6th week of life for the rat offspring. In the course of the experiment a decrease in the iron level in the bones influenced by TCDD was observed. The interaction time multiplied by the pharmacological factor is also important. In group 1, a significant decrease in the iron content was observed in the 24 th week of the experiment. In groups with TCDD a decrease in the Fe content was observed in the 4 th week (Fig. 1 and 2).

Zinc. In group 1 , an exponential growth tendency of $\mathrm{Zn}$ content in the bone material studied was observed during the measurements made in the $1 \mathrm{st}, 4 \mathrm{th}, 6$ th and 24 th week of the experiment.

In groups 2, 3 and 4, the content of $\mathrm{Zn}$ in neonatal rats (1 week) was similar to the content determined in group $1(0.029$ $0.034 \mathrm{mg} \mathrm{g}^{-1}$ ) (Table 1).

In group 3 the content of $\mathrm{Zn}$ increased significantly in the 4 th week, slightly dropped in the 6 th week and in the 24 th week reached the maximum level $(0.074 \pm 0.013)$, higher than in group $1(0.057 \pm 0.008)$ (Table 1$)$.

In group 4, an increase in the $\mathrm{Zn}$ content in the bones in the 24 th week $(0.063 \pm 0.003)$ was observed, in the 4 th and 6 th week the increase was significant. The increase was lower compared with the results observed for group 3 (Table 1).

In the case of zinc, the content in the bones increased with time, and is influenced by TCDD but is not modulated by ASA or $\alpha$-tocopherol in the 1 st, 4 th and 6 th week. In group 4 a content of zinc that was similar to that observed in group 1 was observed in the 24th week. However, the difference between the 2nd, 3rd and 4 th groups was not statistically significant (Fig. 1 and 2).

The relative change in the $\Delta C_{24}(\%)$ content of the chemical element after 24 weeks was calculated on the basis of the following relationship:

$$
\Delta C_{24}(\%)=\frac{C_{24}-C_{1}}{C_{1}} \times 100
$$

In which: $C_{24}=$ chemical element content in the 24 th week (mg $\left.\mathrm{g}^{-1}\right) ; C_{1}=$ content in the 1 st week $\left(\mathrm{mg} \mathrm{g}^{-1}\right)$.
Changes in the average content of elements in the calvaria of the rats from the experimental groups are shown in Fig. 2.

At the beginning of the experiment (in the 1st week) a strong positive correlation between the values of analyzed chemical elements was observed in all groups of animals. In the 24th week, the direction and strength of correlation in group 1 had not changed. However, in groups administered with TCDD no correlations were observed in the case of most elements after 24 weeks. A statistically significant positive correlation between iron $(r=0.446)$ and zinc $(r=0.535)$ with regard to calcium occurred in group 2. In group 4 significant correlations occurred between magnesium and iron $(r=0.808)$ and between zinc and calcium $(r=0.909)$ in the 24 th week.

In the case of the correlation between the iron and calcium, even the direction changed after 24 weeks (rho $=-0.848$ ). The increase in the iron content was accompanied by a decrease in the calcium content (Fig. 3).

\section{Discussion}

Based on the results of experimental studies, it has been shown that TCDD disrupts the structure of the connective tissue, ${ }^{\mathbf{1 5}}$ suppressing the synthesis of collagen I and causing oxidative stress, which is associated with an increase in the concentration of proinflammatory interleukins. ${ }^{16,52}$ Other studies have demonstrated the inhibition of alkaline phosphatase activity by dioxin and that the initiators of mineralization can affect the building of poorly mineralized tissues. ${ }^{16,53}$

In the present study, dynamic changes in the mineral content after indirect dioxin intoxication in rats' calvaria were evaluated. Owing to the fact that this bone is not exposed to mechanical loads, it provides a good and commonly used experimental model for proper reflection of the processes taking place during embryogenesis and postnatal growth. $31,35-37,54-56$

After the birth, the calvaria undergoes an intense process of bone remodeling, which is manifested in our results by a subsequent increase in the calcium content. Increased bone

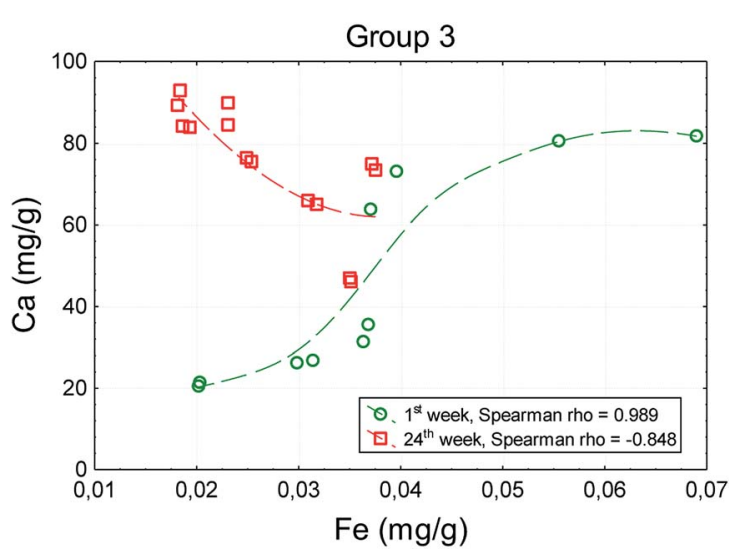

Fig. 3 An example diagram of the correlation between the content of calcium and iron in the bones of animals in group 3 between the 1st and 24th week of the experiment. 
resorption in the rat is associated with the development of the skull which occurs between the 4 th and 6 th week after birth. Then, as a result of the synthesis of new bone tissue and its successive mineralization, the calcium content increases.

The results obtained from the group 1 animals confirm this trend, because the calcium level remains at a constant, low level, for 6 weeks, and then a slow increase is observed.

In group 2, TCDD interferes with bone synthesis in the offspring, which has been proven in previously published studies. As a direct influence on bone cells during embryogenesis, increased bone mineralization followed by resorption at around 6 weeks of life was noted. , 31,33 $^{4}$

Limiting the inflammation process by using $\mathrm{ASA}^{46}$ causes inhibition of osteoclast recruitment, which significantly reduces bone resorption. The natural cycle of bone turnover is disrupted and excessive calcium retention in the bones is observed. Excessive stiffness of the calvaria in the postpartum period undoubtedly has a negative effect on brain development. ${ }^{57,58}$

Compared with group 1, there are significant fluctuations in the level of calcium, zinc and iron in group 2, and there is rapid variability of the content of chemical elements between the 1st and 4th week, with a progressive increase in the level of magnesium in the bones. In this group the level of iron and other elements, except magnesium, increased between the 1st and 4th week. This indicates the ongoing process of bone formation, which means a delay in the calvaria formation process. The dynamics of the decrease in the level of magnesium and zinc were similar to the case for calcium, as described above. In group 2 a markedly increased magnesium content in relation to $\mathrm{Ca}$ is noted. This is due to the incorporation of $\mathrm{Mg}$ into the hydroxyapatite, which may indicate inadequate mineralization. The obtained results concerning the determination of the presence of calcium and magnesium in the calvaria show that $\alpha$-tocopherol improves the calcium and magnesium balance that is disturbed by TCDD. The use of $\alpha$ tocopherol indicates an effective prevention of dioxin intoxication. The results of the elemental composition for all of the elements constituted similar values in the 24 th week. In the case of $\mathrm{Zn}$ and Fe contents, the results obtained after using TCDD + ASA or $\alpha$-tocopherol, are not conclusive. The observed decrease in the Fe content in the calvaria is not associated with osteoresorption, neither ASA nor $\alpha$-tocopherol caused a change in this trend.

These results are in accordance with significant bone hypoplasia occurring in mature individuals from female rats treated with TCDD. ${ }^{11}$ Other authors have also demonstrated the influence of TCDD on the occurrence of changes in the content of calcium in bones, linking it with endocrine changes caused by dioxin affinity to the estrogen receptor for example, which may affect the development of bone. ${ }^{59}$ Research by Gierthy et al. ${ }^{35}$ based on a culture of rat calvarial osteoblasts showed that the administration of TCDD resulted in significant inhibition of the formation of osteoblasts and influenced the expression of alkaline phosphatase and osteocalcin. Moreover, the influence of TCDD on the estrogen levels affects the altered gene expression in osteoblasts during differentiation. ${ }^{35}$ Carpi et al. ${ }^{60}$ showed that TCDD causes bone formation disorders. Other studies on bone stem cells indicated that TCDD decreases the concentration of mRNA and reduces the activity of alkaline phosphatase and osteocalcin, and this decrease is closely correlated with the dose of dioxin. ${ }^{61}$ Naruse et al. ${ }^{62}$ indicated that the influence of dioxin on the culture of mouse osteoblasts demonstrated a decrease in the alkaline phosphatase activity, a reduction in calcium deposits in these cells, and an increase in expression of AhR after the administration of TCDD. The administration of dioxin to pregnant females caused an inhibition of the normal process of bone tissue calcification. ${ }^{62}$

Changes in the calcium and magnesium content may be associated with the proinflammatory action of dioxin. ${ }^{31}$ It was shown that the activation of two pathways of inflammation: by stimulation of interleukin production and through cyclooxygenase 2 (COX-2) activation, have an influence on the process of bone mineralization. These effects have been revealed in archaeological bone material. ${ }^{50}$ Other studies showed that the use of $\alpha$-tocopherol in high doses for a period of 3 weeks following the administration of TCDD contributed to a significant reduction in IL-6 and TNF and also protected collagen against degradation. ${ }^{3}$ The administration of ASA for a period of 3 weeks following the application of TCDD was aimed at reducing the inflammatory reaction induced by the stimulation of COX-2. There are also reports that the use of ASA in high doses blocks COX-2..$^{36,47,63}$ The anti-inflammatory properties of ASA constitute a valuable addition to the antagonistic effect of this drug on the aryl hydrocarbon receptor. ${ }^{36,38}$

It is worth mentioning that in the literature there is only a small amount of data concerning the influence of TCDD on the content of magnesium, zinc and iron in bones. ${ }^{64}$ It was shown that the administration of TCDD contributed to changes in the content of magnesium in the cytosol of liver cells. ${ }^{27}$ On the other hand, research by Keller et al. showed a significant reduction in the level of magnesium, as well as a decrease in the concentration of alkaline phosphatase. ${ }^{65}$

The results indicate a significant reduction of the negative effects of dioxin to offspring after intoxication of the mother and also the preventive role of $\alpha$-tocopherol which can reduce the level of dioxin end products in the mother's body and reduce its transfer via the placenta and milk.

Changes over time have been observed in the bone mineralization dynamics in offspring, characterized by the similar content of elements measured at weeks 1 and 24, but the contents were completely different in the intermediate periods. Intermediate periods are crucial for the final formation of the calvaria and brain development, which undergoes dynamic changes during the formation of the calvaria.

The effects of ASA and $\alpha$-tocopherol are different and mainly consist of the inhibition of processes of bone tissue remodeling, in which $\alpha$-tocopherol maintains the same level of mineralization as in healthy tissue.

\section{Conclusions}

TCDD indirectly disturbs the process of mineralization and bone turnover in the calvaria of offspring. The use of $\alpha$ - 
tocopherol normalizes the processes of bone resorption and formation, maintaining the content of the studied elements at a physiological level. Administration of ASA limits bone resorption processes, which affects the content of the elements important to bone formation.

\section{Conflicts of interest}

There are no conflicts to declare.

\section{Acknowledgements}

This work was supported by grant 28/Pbmn from the Wroclaw Medical University. Moreover, financial support from the National Science Centre over the course of the realization of the project 'Preparation and characterization of biocomposites based on nanoapatites for theranostic', no. UMO-2015/19/B/ ST5/01330, is gratefully acknowledged. The authors would like to thank Prof. PhD Ireneusz Calkosinski (1951-2017) for inspiration and his helpful advice and assistance in organizing the welfare of the animals.

\section{References}

1 M. Dobrzynski, I. Calkosinski, I. Przywitowska, et al., Effects of dioxins in environmental pollution on development of tooth disorders, Pol. J. Environ. Stud., 2009, 18(3), 319-323.

2 IARC, Polychlorinated dibenzo-para-dioxins and polychlorinated dibenzofurans, IARC Monogr. Eval. Carcinog. Risks Hum., 1997, 69, 33-343.

3 I. Calkosinski, J. Rosinczuk-Tonderys, M. Szopa, M. Dobrzynski and A. Gamian, High doses of tocopherol in the prevention and potentiation of dioxin in experimental inflammation - potential application, Postepy Hig. Med. Dosw., 2011, 65, 143-157, DOI: 10.5604/17322693.935120.

$4 \mathrm{M}$. Dobrzynski, The influence of tocopherol and acetylsalicylic acid on tooth organ structure in offspring of rat dams undergoing 2,3,7,8-tetrachlorodibenzo- $p$-dioxin (TCDD), Doctoral thesis, Wroclaw Medical University, 2012.

$5 \mathrm{~J}$. Koistinen, H. Kiviranta, P. Ruokojärvi, et al., Organohalogen pollutants in herring from the northern Baltic Sea: concentrations, congener profiles and explanatory factors, Environ. Pollut., 2008, 154(2), 172-183, DOI: 10.1016/j.envpol. 2007.10.019.

6 N. S. Fracchiolla, C. Annaloro, F. Guidotti, B. Fattizzo and A. Cortelezzi, 2,3,7,8-Tetrachlorodibenzo-p-dioxin (TCDD) role in hematopoiesis and in hematologic diseases: A critical review, Toxicology, 2016, 374, 60-68, DOI: 10.1016/ j.tox.2016.10.007.

7 S. Kanan and F. Samara, Dioxins and furans: A review from chemical and environmental perspectives, Trends Environ. Anal. Chem., 2018, 17, 1-13, DOI: 10.1016/j.teac.2017.12.001.

8 I. Calkosinski, J. Rosinczuk-Tonderys, M. Dobrzynski, L. Palka and J. Bazan, Occurrence of disseminated intravascular coagulation in 2,3,7,8-tetrachlorodibenzo- $p$ dioxin-induced pneumonia in the rat, Adv. Exp. Med. Biol., 2013, 788, 283-292, DOI: 10.1007/978-94-007-6627-3-39.
9 H. Fiedler, National PCDD/PCDF release inventories under the Stockholm Convention on Persistent Organic Pollutants, Chemosphere, 2007, 67(9), S96-S108, DOI: 10.1016/j.chemosphere. 2006.05.093.

10 O. Sorg, M. Zennegg, P. Schmid, et al., 2,3,7,8tetrachlorodibenzo- $p$-dioxin (TCDD) poisoning in Victor Yushchenko: identification and measurement of TCDD metabolites, Lancet, 2009, 374(9696), 1179-1185, DOI: 10.1016/S0140-6736(09)60912-0.

11 M. Dobrzynski, I. Calkosinski, I. Przywitowska, et al.,Effects of dioxins in environmental pollution on development of tooth disorders, Pol. J. Environ. Stud., 2009, 18(3), 319-323.

12 F. P. Guengerich, Reactions and significance of cytochrome P-450 enzymes, J. Biol. Chem., 1991, 266(16), 10019-10022.

13 D. Palut, G. Kostka and P. Strucinski, The role of nuclear receptors in cytochrome P-450 induction by xenochemicals, J. Controlled Release, 2002, 53(4), 321-332.

14 A. B. Okey, An Aryl Hydrocarbon Receptor Odyssey to the Shores of Toxicology: The Deichmann Lecture, International Congress of Toxicology-XI, Toxicol. Sci., 2007, 98(1), 5-38, DOI: 10.1093/toxsci/kfm096.

15 E. A. Andreasen, L. K. Mathew, C. V. Löhr, R. Hasson and R. L. Tanguay, Aryl Hydrocarbon Receptor Activation Impairs Extracellular Matrix Remodeling during Zebra Fish fin Regeneration, Toxicol. Sci., 2007, 95(1), 215-226, DOI: 10.1093/toxsci/kfl119.

16 S. U. Singh, R. F. Casper, P. C. Fritz, et al., Inhibition of dioxin effects on bone formation in vitro by a newly described aryl hydrocarbon receptor antagonist, resveratrol, J. Endocrinol., 2000, 167(1), 183-195, DOI: 10.1677/joe.0.1670183.

17 K. Gostomska-Pampuch, A. Ostrowska, P. Kuropka, et al.Protective effects of levamisole, acetylsalicylic acid, and $\alpha$-tocopherol against dioxin toxicity measured as the expression of AhR and COX-2 in a chicken embryo model, Histochem. Cell Biol., 2017, 147(4), 523-536, DOI: 10.1007/ s00418-016-1528-2.

18 J. Mimura and Y. Fujii-Kuriyama, Functional role of AhR in the expression of toxic effects by TCDD, Biochim. Biophys. Acta, 2003, 1619(3), 263-268, DOI: 10.1016/S0304-4165(02) 00485-3.

19 M. K. Walker, R. S. Pollenz and S. M. Smith, Expression of the Aryl Hydrocarbon Receptor (AhR) and AhR Nuclear Translocator during Chick Cardiogenesis Is Consistent with 2,3,7,8-Tetrachlorodibenzo- $p$-dioxin-Induced Heart Defects, Toxicol. Appl. Pharmacol., 1997, 143(2), 407-419, DOI: $10.1006 /$ TAAP.1996.8068.

20 L. E. Gray and J. S. Ostby, Utero 2,3,7,8-Tetrachlorodibenzop-dioxin (TCDD) Alters Reproductive Morphology and Function in Female Rat Offspring, Toxicol. Appl. Pharmacol., 1995, 133(2), 285-294, DOI: 10.1006/ TAAP.1995.1153.

21 L. A. Couture, B. D. Abbott and L. S. Birnbaum, A critical review of the developmental toxicity and teratogenicity of 2,3,7,8-tetrachlorodibenzo- $p$-dioxin: Recent advances toward understanding the mechanism, Teratology, 1990, 42(6), 619-627, DOI: 10.1002/tera.1420420606. 
22 A. di Domenico, V. Silano, G. Viviano and G. Zapponi, Accidental release of 2,3,7,8-tetrachlorodibenzo- $p$-dioxin (TCDD) at Sèveso, Italy: II. TCDD distribution in the soil surface layer, Ecotoxicol. Environ. Saf., 1980, 4(3), 298-320, DOI: 10.1016/0147-6513(80)90032-9.

23 J. E. Michalek, F. Z. Akhtar, M. P. Longnecker and J. E. Burton, Relation of Serum 2,3,7,8-Tetrachlorodibenzo$p$-Dioxin (TCDD) Level to Hematological Examination Results in Veterans of Operation Ranch Hand, Arch. Environ. Health, 2001, 56(5), 396-405, DOI: 10.1080/ 00039890109604474.

24 M. Neuberger, W. Landvoigt and F. Derntl, Blood levels of 2,3,7,8-tetrachlorodibenzo- $p$-dioxin in chemical workers after chloracne and in comparison groups, Int. Arch. Occup. Environ. Health, 1991, 63(5), 325-327, DOI: 10.1007/ BF00381582.

25 R. Pohjanvirta and J. Tuomisto, Short-term toxicity of 2,3,7,8tetrachlorodibenzo- $p$-dioxin in laboratory animals: effects, mechanisms, and animal models, Pharmacol. Rev., 1994, 46(4), 483-549. http://www.ncbi.nlm.nih.gov/pubmed/ 7899475, .

26 Z. Z. Wahba, Z. A. F. Al-Bayati and S. J. Stohs, Effect of 2,3,7,8Tetrachlorodibenzo- $p$-dioxin on the Hepatic Distribution of Iron, Copper, Zinc, and Magnesium in Rats, J. Biochem. Toxicol., 1988, 3(2), 121-129, DOI: 10.1002/jbt.2570030206.

27 J. G. Vos, J. A. Moore and J. G. Zinkl, Effect of 2,3,7,8tetrachlorodibenzo- $p$-dioxin on the immune system of laboratory animals, Environ. Health Perspect., 1973, 5, 149162, DOI: 10.1289/ehp.7305149.

28 O. Jablonska, Z. Shi, K. E. Valdez, A. Y. Ting and B. K. Petroff, Temporal and anatomical sensitivities to the aryl hydrocarbon receptor agonist 2,3,7,8-tetrachlorodibenzo- $p$ dioxin leading to premature acyclicity with age in rats, Int. J. Androl., 2010, 33(2), 405-412, DOI: 10.1111/j.13652605.2009.01031.x.

29 G. A. Fox, R. Lundberg, C. Wejheden, et al., Health of Herring Gulls (Larus argentatus) in Relation to Breeding Location in the Early 1990s. III. Effects on the Bone Tissue, J. Toxicol. Environ. Health, Part A, 2008, 71(21), 1448-1456, DOI: $10.1080 / 15287390802328788$.

30 H. M. Thompson, A. Fernandes, M. Rose, S. White and A. Blackburn, Possible chemical causes of skeletal deformities in grey heron nestlings (Ardea cinerea) in North Nottinghamshire, UK, Chemosphere, 2006, 65(3), DOI: 10.1016/j.chemosphere.2006.02.007.

31 M. Dobrzynski, P. Kuropka, M. Tarnowska, et al., The protective effect of $\alpha$-tocopherol on the content of selected elements in the calvaria for exposed hens to TCDD in the early embyonic period, Biol. Trace Elem. Res., 2018, DOI: 10.1007/s12011-018-1580-y.

32 G. Della Pepa and M. L. Brandi, Microelements for bone boost: the last but not the least, Clin. Cases Miner. Bone Metab., 2016, 13(3), 181-185, DOI: 10.11138/ccmbm/ 2016.13.3.181.

33 M. Dobrzynski, C. Pezowicz, M. Tomanik, et al., Modulating effect of selected pharmaceuticals on bone in female rats exposed to 2,3,7,8-tetrachlorodibenzo-p-dioxin (TCDD), $R S C$ Adv., 2018, 8(48), 27537-27545, DOI: 10.1039/C8RA03619E.

34 M. A. Finnila, P. Zioupos, M. Herlin, et al. Effects of 2,3,7,8tetrachlorodibenzo- $p$-dioxin exposure on bone material properties, J. Biomech., 2010, 43(6), 1097-1103, DOI: 10.1016/j.jbiomech.2009.12.011.

35 J. F. Gierthy, J. B. Silkworth, M. Tassinari, G. S. Stein and J. B. Lian, 2,3,7,8-Tetrachlorodibenzo- $p$-dioxin inhibits differentiation of normal diploid rat osteoblasts in vitro, $J$. Cell. Biochem., 1994, 54(2), 231-238, DOI: 10.1002/ jcb.240540211.

36 C. J. MacDonald, H. P. Ciolino and G. C. Yeh, The drug salicylamide is an antagonist of the aryl hydrocarbon receptor that inhibits signal transduction induced by 2,3,7,8-tetrachlorodibenzo-p-dioxin, Cancer Res., 2004, 64(1), 429-434.

37 N. Nishimura, H. Nishimura, T. Ito, et al., Dioxin-induced up-regulation of the active form of vitamin $\mathrm{D}$ is the main cause for its inhibitory action on osteoblast activities, leading to developmental bone toxicity, Toxicol. Appl. Pharmacol., 2009, 236(3), 301-309, DOI: 10.1016/ J.TAAP.2009.01.025.

38 E. Kloser, S. Böhmdorfer, L. Brecker, et al., Synthesis of 5(Fluorophenyl)tocopherols as Novel Dioxin Receptor Antagonists, Eur. J. Org. Chem., 2011, 2011(13), 2450-2457, DOI: $10.1002 /$ ejoc. 201100178.

39 M. Dobrzynski, U. Kaczmarek, P. Kuropka, et al., Tooth development disorders in infants of rat dams exposed to 2,3,7,8-tetrachlorodibenzo- $p$-dioxin and protective role of tocopherol and acetylsalicylic acid, Pol. J. Vet. Sci., 2017, 20(4), 769-778, DOI: 10.1515/pjvs-2017-0097.

40 I. Calkosinski, J. Rosinczuk-Tonderys, A. BronowickaSzydelko, et al., Effect of tocopherol on biochemical blood parameters in pleuritis-induced rats treated with $2,3,7,8$ tetrachlorodibenzo-p-dioxin, Toxicol. Ind. Health, 2015, 31(6), 510-522, DOI: 10.1177/0748233713475497.

41 O. Ciftci, M. Aydin, İ. Ozdemir and N. Vardi, Quercetin prevents 2,3,7,8-tetrachlorodibenzo- $p$-dioxin-induced testicular damage in rats, Andrologia, 2012, 44(3), 164-173, DOI: 10.1111/j.1439-0272.2010.01126.x.

42 F. Oguz, O. Ciftci, M. Aydın, et al., Aminoguanidine prevents testicular damage-induced-2,3,7,8-tetrachlorodibenzo- $p$ dioxin (TCDD) in male rats, Andrologia, 2013, 45(4), 225231, DOI: 10.1111/j.1439-0272.2012.01334.x.

43 N. P. Singh, U. S. Singh, M. Nagarkatti and P. S. Nagarkatti, Resveratrol (3,5, $4^{\prime}$-trihydroxystilbene) protects pregnant mother and fetus from the immunotoxic effects of 2,3,7,8tetrachlorodibenzo- $p$-dioxin, Mol. Nutr. Food Res., 2011, 55(2), 209-219, DOI: 10.1002/mnfr.201000206.

44 J. Ma, Z. Cai, H. Wei, X. Liu, Q. Zhao and T. Zhang, The antitumor effect of aspirin: What we know and what we expect, Biomed. Pharmacother., 2017, 95, 656-661, DOI: 10.1016/ j.biopha.2017.08.085.

45 R. Jirmář and P. Widimský, Enteric-coated aspirin in cardiac patients: Is it less effective than plain aspirin?, Cor Vasa, 2018, 60(2), e165-e168, DOI: 10.1016/J.CRVASA.2017.05.011. 
46 D. C. Bauer, E. S. Orwoll, K. M. Fox, et al., Aspirin and NSAID use in older women: Effect on bone mineral density and fracture risk, J. Bone Miner. Res., 2009, 11(1), 29-35, DOI: 10.1002/jbmr.5650110106.

47 L. D. Carbone, F. A. Tylavsky, J. A. Cauley, et al., Association Between Bone Mineral Density and the Use of Nonsteroidal Anti-Inflammatory Drugs and Aspirin: Impact of Cyclooxygenase Selectivity, J. Bone Miner. Res., 2003, 18(10), 1795-1802, DOI: 10.1359/jbmr.2003.18.10.1795.

48 A. Azzi, Many tocopherols, one vitamin E, Mol. Aspects Med., 2018, 61, 92-103, DOI: 10.1016/j.mam.2017.06.004.

49 A. Ostrowska, K. Gostomska-Pampuch, A. Leskow, et al., Expression of advanced glycation end-products and NFкB in chick embryos exposed to dioxins and treated with acetylsalicylic acid and $\alpha$-tocopherol, Poult. Sci., 2017, 96(6), 1874-1883, DOI: 10.3382/ps/pew450.

50 M. Dobrzynski, P. Kuropka, A. Leskow, K. Herman, M. Tarnowska and R. J. Wiglusz, Co-expression of the aryl hydrocarbon receptor and estrogen receptor in the developing teeth of rat offspring after rat mothers' exposure to 2,3,7,8-tetrachlorodibenzo- $p$-dioxin and the protective action of $\alpha$-tocopherol and acetylsalicylic acid, Adv. Clin. Exp. Med., 2019, DOI: 10.17219/acem/99613.

51 European standard commitee, Food Products - Determination of Trace Elements - Pressure Mineralization, 2014, vol. 14. http://www.sklep.pkn.pl/pn-en-13805-2014-11e.html.

52 I. Calkosinski, J. Rosinczuk-Tonderys, J. Bazan, et al., The influence of dioxin intoxication on the human system and possibilities of limiting its negative effects on the environment and living organisms, Ann. Agric. Environ. Med., 2014, 21(3), 518-524, DOI: 10.5604/12321966.1120594.

53 A. Kiukkonen, M. Viluksela, C. Sahlberg, et al., Response of the Incisor Tooth to 2,3,7,8-Tetrachlorodibenzo- $p$-dioxin in a Dioxin-Resistant and a Dioxin-Sensitive Rat Strain, Toxicol. Sci., 2002, 69(2), 482-489, DOI: 10.1093/toxsci/ 69.2.482.

54 A. Aybar Odstrcil, E. Territoriale and L. Missana, An experimental model in calvaria to evaluate bone therapies, Acta Odontol. Latinoam., 2005, 18(2), 63-67, http:// www.ncbi.nlm.nih.gov/pubmed/16673794, .

55 P. S. Gomes and M. H. Fernandes, Rodent models in bonerelated research: the relevance of calvarial defects in the assessment of bone regeneration strategies, Lab. Anim., 2011, 45(1), 14-24, DOI: 10.1258/la.2010.010085.

56 H. Jiang, Y. Wang, Z. Deng, et al., Construction and Evaluation of a Murine Calvarial Osteolysis Model by
Exposure to CoCrMo Particles in Aseptic Loosening, J. Vis. Exp., 2018, 132, DOI: 10.3791/56276.

57 L. Juricek, X. Coumoul, L. Juricek and X. Coumoul, The Aryl Hydrocarbon Receptor and the Nervous System, Int. J. Mol. Sci., 2018, 19(9), 2504, DOI: 10.3390/ijms19092504.

58 Y. Kobayashi, T. Hirano, T. Omotehara, et al., Immunohistochemical analysis of 2,3,7,8tetrachlorodibenzo-p-dioxin (TCDD) toxicity on the developmental dentate gyrus and hippocampal fimbria in fetal mice, J. Vet. Med. Sci., 2015, 77(11), 1355-1361, DOI: 10.1292/jvms.15-0238.

59 F. Ohtake, K. Takeyama, T. Matsumoto, et al., Modulation of oestrogen receptor signalling by association with the activated dioxin receptor, Nature, 2003, 423(6939), 545-550, DOI: $10.1038 /$ nature01606.

60 D. Carpi, M. Korkalainen, L. Airoldi, et al., Dioxin-Sensitive Proteins in Differentiating Osteoblasts: Effects on Bone Formation In Vitro, Toxicol. Sci., 2009, 108(2), 330-343, DOI: 10.1093/toxsci/kfp021.

61 M. Korkalainen, E. Kallio, A. Olkku, et al., Dioxins interfere with differentiation of osteoblasts and osteoclasts, Bone, 2009, 44(6), 1134-1142, DOI: 10.1016/j.bone.2009.02.019.

62 M. Naruse, Y. Ishihara, S. Miyagawa-Tomita, A. Koyama and H. Hagiwara, 3-Methylcholanthrene, Which Binds to the Arylhydrocarbon Receptor, Inhibits Proliferation and Differentiation of Osteoblasts in vitro and Ossification in vivo, Endocrinology, 2002, 143(9), 3575-3581, DOI: 10.1210/ en.2002-220003.

63 C. J. MacDonald, R. Y. S. Cheng, D. D. Roberts, D. A. Wink and G. C. Yeh, Modulation of Carcinogen Metabolism by Nitric Oxide-Aspirin 2 Is Associated with Suppression of DNA Damage and DNA Adduct Formation, J. Biol. Chem., 2009, 284(33), 22099-22107, DOI: 10.1074/jbc.M109.021063.

64 P. Kuropka, M. Dobrzynski, K. Herman, et al., Evaluation of the protective influence of various doses of $\alpha$-tocopherol on the zinc and iron level in the bone tissue of rat offspring after exposure to 2,3,7,8-tetrachlorodibenzo-p-dioxin, Pol. J. Environ. Stud., 2015, 24(6A), 188-193.

65 J. M. Keller, J. R. Kucklick, M. A. Stamper, C. A. Harms and P. D. McClellan-Green, Associations between Organochlorine Contaminant Concentrations and Clinical Health Parameters in Loggerhead Sea Turtles from North Carolina, USA, Environ. Health Perspect., 2004, 112(10), 1074-1079, DOI: 10.1289/ehp.6923. 